This is the peer reviewed version of the following article:

Brasili C, Calia P, Monasterolo I. Mapping citizens' identification with the EU. Reg Sci Policy Pract. 2019; 1-18. DOI: 10.1111/rsp3.12227

which has been published in final form at https://doi.org/10.1111/rsp3.12227

This article may be used for non-commercial purposes in accordance with Wiley

Terms and Conditions for Use of Self-Archived Versions. 


\title{
Mapping citizens' identification with the EU
}

\author{
Cristina Brasili, Pinuccia Calia, Irene Monasterolo
}

\section{Abstract}

Do citizens show different patterns of European identification? Are the results driven by specific regional characteristics? Has Cohesion Policy an influence on EU citizens' identification?

With the aim to answer these questions, we develop a novel probabilistic model that allows classification of citizens according to their different patterns of identification with Europe and the European project. This model exploits the heterogeneity of citizens' identification patterns across the European regions and how they are influenced by individual and regional characteristics. The results of the analysis at regional level are presented with regards to nine case-study regions. The model builds on PERCEIVE's research results that develop the theoretical framework for the definition and measurement of the level of identification with EU and its drivers.

Keywords: EU Cohesion Policy, citizens' identification, citizens’ perception, EU regions, EU project, IdentEU, clusters.

\section{Introduction ${ }^{1}$}

Current political developments in the European Union (EU) drove scholars' attention to the role of regional and local socio-economic factors and of the EU Cohesion Policy in the building up of European citizens' identification with the EU project (Bauhr and Charron, 2018; Royuela, 2018), where the concept of "EU project" allows us to embrace the multifaceted and broad concept of EU integration, which entails economic, social, political and financial aspects. The EU Cohesion Policy, implemented at regional level since 1989, absorbs one third of the EU budget with the aim to support the social and economic development and address specific regional development challenges. Thus, it represents the material realization of the EU project in the daily life of citizens (Capello and Perucca, 2019). Nevertheless, there are few attempts to research citizens' identification with the EU at the regional level in the context of EU Cohesion Policy. Moreover, development and implementation of a quantitative modelling approach to assess citizens' identification is still missing. Quantifying EU citizens' identification requires embracing new challenges that pertain both the development of standardized, robust methodologies, and the analysis of the results at the light of EU policies, of which the Cohesion Policy represents a main pillar (Aiello et al., 2018).

\footnotetext{
${ }^{1}$ The authors acknowledge the support from the European Union's Horizon 2020, Research and Innovation Program, under the PERCEIVE project, Perception and Evaluation of Regional and Cohesion policies by Europeans and Identification with the values of Europe, Grant Agreement number 693529.
} 
Our paper contributes to this stream of research by introducing a novel probabilistic model for the assessment of citizens' identification at individual and regional level in order to discover regional patterns of citizens' identification. In particular, we present and discuss the results of a model, IdentEU (Aiello et al. 2018), which builds on a rich set of information collected with structured interviews (Bauhr and Charron, 2019) and complemented by secondary data at regional level (e.g. from Eurostat). This provides the opportunity to more deeply consider the socio-economic and political determinants of citizens' identification with the EU project.

This paper presents the empirical results at regional level focusing on nine EU case-study regions that represent the complex and heterogeneous reality of the performance of the EU Cohesion Policy and its multidimensional determinants in terms of socio-economic, political and demographic characteristics. These have been the object of a deep qualitative and quantitative analysis carried on within PERCEIVE project (Aiello et al., 2017), including the implementation of the EU Cohesion Policy by Local Managing Authorities (via the design and implementation of focus groups, SWOT analysis and the review of the regional Operational Programs). General results of regional analysis are discussed in Brasili et al. (forthcoming).

The model is theoretically grounded on the concept of individual identification with Europe derived from social psychology, defined as “citizens' self-categorization as European together with their evaluations of their membership in the European collective and their affective attachment to Europe and other Europeans" (Bergbauer, 2018, p.18). Thus, individual identification involves cognitive, affective and evaluative dimensions of identity:

- the cognitive component refers to self-categorization as European;

- the evaluative component refers to the assignment of value connotation (negative/positive) to their membership in the European collective;

- the affective component refers to the emotional attachment and feeling of love and concern for Europe and other European.

Understanding why and to what extent EU citizens identify (or not) with the EU institutions is gaining momentum with recent political developments in the EU. This is characterized by signals of “enlargement fatigue" and growing citizens' skepticism towards its institutions (for instance the case of Brexit) and the Euro. In this regard, there is an urgent need to understand the socio-economic drivers of citizens' attitudes toward the EU, both at individual and regional level, as well as to foster a better knowledge of the factors characterizing EU citizens' identification with the EU project. This information is policy-relevant, in so far as it contributes to understanding the drivers of the observed gap between EU institutions and citizens in an historical period characterized by growing citizens' mistrust in the EU institutions. 
The manuscript is structured as follows. Section 2 describes the innovativeness and added value on the state of the art represented by the IdentEU model, and the complementarity of our results with the literature. Section 3 describes the data used, focusing on the data obtained from the PERCEIVE survey. Section 4 discusses the results in terms of citizens' perception and identification with the EU project (section 4.1), the role of individual characteristics and the context (section 4.2), and the regional analysis on the nine case-study regions (section 4.3). Section 5 presents conclusions and policy recommendations for EU decision-makers.

\section{Methodology}

We contribute to the understanding of citizens' perception and identification with the EU project by focusing on the socio-economic, demographic and policy characteristics at the regional and individual level. The existing research on European identity and citizens' attitudes towards the EU Cohesion Policy (Mendez and Bachtler, 2017, Lopez-Bazo and Royuela, 2017) shows a distinction between the cognitive, affective and evaluative dimensions of identity. Using the results of the Eurobarometer's surveys, Capello and Perucca (2019) find that citizens' awareness and satisfaction of the Cohesion Policy are mediated by the presence of local context conditions that characterize different kinds of policy implementation settings, finding that "individual / private / subjective" needs have to be fulfilled independently from the capacity of EU actions in meeting regions' needs. Then, Dąbrowski et al. (2018), using Eurobarometer's surveys, develop a regional typology of EU identification based on hierarchical cluster analysis and identify five distinctive regional types of EU identification, from negative to neutral to positive. Borz et al. (2018) develop a survey in 17 regions across 12 EU member states, finding that knowledge of Cohesion Policy matters for developing a European identity. The awareness of the Cohesion Fund matters more than awareness of the European Regional Development Fund or the European Social Fund, while the exposure to EU funded projects increases the likelihood of developing a Europeanized identity.

By exploiting the rich information of the PERCEIVE survey (Bauhr and Charron, 2018, 2019) the determinants of EU identity and individual identification have been discussed from an empirical point of view by Lopez-Bazo and Royuela (2017). They identify and group the main influences: Political capital, Ideology, Socio-economic context, Country level variables. Finally, Royuela (2018) uses a fuzzy sets method to build a Composite Index of European Identity (CI_Eu_Ident), finding that Eastern European countries show higher levels of the European Identity while the United Kingdom, France, Sweden and the Netherlands have the lowest scores. Higher education and higher income are 
positively correlated with higher values of EU identification, while demographic and gender variables have negligible effects.

Our analysis complements existing research by introducing both conceptual and methodological innovations. First, we extend the study of citizens' identification downscaling it at the regional (Nuts2 level) and individual level. Second, we exploit the PERCEIVE dataset of micro-level data ${ }^{2}$ that collects the positions of citizens on different aspects of EU membership and identification, their perception on the functioning of the EU institutions and on the founding values of the EU project. This overcomes some of the main issues related to the measurement of European identity (Bruter, 2008) and identification at different spatial levels. Third, we report the results of the probabilistic classification model (IdentEU model) that provides a quantitative measurement of the concept of identification with EU at both individual and regional level. This takes into account the different dimensions underlining the concept of individual identification and disclose patterns of identification with the EU described by different attitudes on specific aspects. This model produces a classification of citizens depending on the level and pattern of identification and defines a classification of the EU regions into groups with common profiles of degree of identification, consistently with the emerging pattern of citizens' classification. These innovations are important for studying the influence of regional context on identification, and in particular to understand what role (if any) the Cohesion Policy plays in the relation between EU citizens and the EU project.

The model builds on Latent Class Analysis (LCA) and multilevel modelling to develop a Hierarchical Latent Class (LC) model (Hagenaars and McCutcheon, 2002; Vermunt, 2003; Skrondal and RabeHesketh, 2004) to explore the multidimensional nature of the concept of identification with the EU project. Latent Class Analysis (LCA) allows the identification of different subpopulations described by a latent categorical variable (identification) that explains the associations among a set of categorically observed indicators (manifest variables).

Using the responses to $\mathrm{K}$ interrelated categorically items $Y_{i j k}$, - response to item $k$ of person $i$ coming from region $j$ - the model identify $\mathrm{T}$ classes of a latent variable $X_{i j}$ : the latent classes $t=1, \ldots, \mathrm{T}$ (clusters) represent the unobservable levels of citizens' identification and each latent class is described by the pattern of responses to the $\mathrm{K}$ items (indicators) with the highest probability in that class (Standard LC Model). Also, considering individuals nested into regions, the model accounts for unobserved regional effects on identification modelled as a discrete latent variable $W_{j}$, whose categories $m=1, \ldots, \mathrm{M}$ describe groups (latent types) of regions for which the parameters in the model

\footnotetext{
${ }^{2}$ Data are from a survey developed as part of the activities of the PERCEIVE project.
} 
differs. In this way, we can obtain a classification of the regions into a small number $M$ of latent classes. Hence, identification with the EU is described by discrete latent variables at two levels, individual and regional, to which citizens and regions are allocated with certain probabilities. Although it is possible to consider identification as a latent continuous variable as in factor analysis, assuming a discrete latent variable allows us to define different patterns of identification according to the different profiles of respondents and to analyze their features ${ }^{3}$.

As a main feature, the model accounts for the effect of individual $\boldsymbol{Z}_{i j}$ and regional characteristics $\boldsymbol{Z}_{j}^{g}$ on the probabilities of class membership ${ }^{4}$. Three types of probabilities are estimated using a multinomial logit specification with different parameters for each of them:

1. $P\left(W_{j}=m \mid Z_{j}^{g}\right)$ : the probability that region $j$ belongs to the latent class $m$ of $W_{j}$, given the regional covariates. It depends on the category effect $\alpha_{0 m}$ of the specific latent class $m$ at regional level and on the effects of the contextual (regional) covariates on $W_{j}$. It describes the distribution of the population among the regional classes.

2. $P\left(X_{i j}=t \mid W_{j}=m, Z_{i j}\right)$ : the probability that the respondent $i$ in region $j$ belongs to the latent class $t$ of $X_{i j}$, given regional latent class membership and the individual covariates. It depends on the category effect $\gamma_{0 t m}$ of $X_{i j}$ specific to the regional latent class $m$, and on the individual level covariates. It delivers information about the distribution of the population among the individual classes.

3. The conditional probability of individual response pattern $\prod_{k=1}^{K} P\left(Y_{i j k}=s_{k} \mid X_{i j}=t, W_{j}=m\right)$ : is the joint probability that the $i$-th respondent has the response pattern $s_{i}$ (for all the $\mathrm{K}$ indicators) given individual and regional latent class membership. This depends on a specific effect of the response category $\beta_{0 s_{k}}$ and on the main effect $\beta_{1 s_{k} t}$ of the individual latent variable $X_{i j}$. It delivers information for describing the latent classes.

\section{Data description}

For building the model we rely on data from a sample survey developed within the PERCEIVE project (Bauhr and Charron, 2018 and 2019) and a dataset that brings together information from several official secondary sources at regional level (NUTS1 and NUTS2) in a panel format (Charron, 2017).

\footnotetext{
${ }^{3}$ More details on the model are in the PERCEIVE - Deliverable 2.4, Section 3.1 (Aiello et al. 2018)

${ }^{4}$ The superscript $g$ identifies the group-level covariates, i.e. regional level variables that are constant for all the individuals in the same region.
} 
The survey collects information from a sample of 17.147 individuals of 18 years of age or older from 15 EU member States ${ }^{5}$, for a total of 153 regions $^{6}$, and was conducted during the summer of 2017. There are 2000 observations for Italy, Poland and Spain; 1500 for France, Germany and UK; 1000 for Austria, Slovakia, Hungary and Romania; about 500 for each other country analyzed.

We use the answers to 10 questions identified below to define the manifest variables $Y_{i j k}$. These, in turn, are used to identify the latent classes at individual and regional levels and to classify citizens and regions according to their level of identification with the EU project. These variables should capture the different components underling the individual identification described in section 1, i.e. "Self-categorization", "Membership evaluation", "Affective attachment”. However, the following categorization aims only to guide the selection of different items that may approximate each dimension and does not have any consequence for the empirical results.

Regarding self-categorization to EU, we use a variable that measures the strength of identification with Europe and another that compares it to the level of identification with the own country:

- How strongly identify with Europe: 1 (Not strongly); 2 (Somewhat strongly); 3 (Strongly).

- Identification with EU vs Country: 1 (Less); 2 (Equal); 3 (More)

These two variables are used for a general assessment of the European identity, as suggested by Bruter (2008). We also consider to what extent the respondent is familiar with the Cohesion Policy:

- Awareness of Cohesion Policy (according to different synonyms): 0 (None); 1 (Only local projects); 2 (At least one among Cohesion Policy, Regional Policy, Structural Funds).

We expect that awareness of Cohesion Policy, one of the main policies implemented by EU, can reinforce self-recognition as a member of the European community, as well as its affective attachment to the EU, hence it may alike be related to the affective component. Actually, for the purpose of empirical analysis, such distinction makes no difference at all.

To account for the "EU membership evaluation" component, we use five variables, the first reporting how the respondent evaluates the membership of her/his own country to the EU:

- Evaluation of country's EU membership: 1 (Good thing); 0 (Bad thing / Neither good nor bad)

\footnotetext{
${ }^{5}$ France, Germany, Austria, United Kingdom, Sweden, the Netherlands, Italy, Spain, Romania, Hungary, Bulgaria, Slovakia, Latvija, Poland, and Estonia.

6 The regional aggregation is at level NUTS2 for most of the countries in the sample, except for Germany, UK and Sweden (NUTS1 level), and for Latvija and Estonia (country level).
} 
This variable has been used by Verhaegen et al. (2014) to measure support for European integration that many authors recognize is influenced by a common European identity (Bruter, 2003; Habermas, 2011). However, European identity goes beyond a positive or negative attitude about European integration (Verhaegen et al., 2014) and the direction of causality is still a debated issue (Hobolt and de Vries, 2016).

Two variables report how the citizens evaluate EU institutions' effectiveness at dealing with the main problem faced by the region where they live and if EU institutions are less / equal /more effective than national government:

- Effectiveness of EU institutions at dealing with the problems in the region: 1 (Not so effective); 2 (Somewhat effective); 3 (Very effective)

- Effectiveness of EU vs National institutions: 1 (Less effective); 2 (Equal effective); 3 (More effective).

Finally, two variables deal with the perception of the level of corruption in EU institutions and compared to corruption in national government:

- Level of corruption in EU: 1 (Low); 2 (Medium); 3 (High)

- Corruption in EU vs National government: 1 (Less corruption); 2 (Equal); 3 (More Corruption)

Two variables account for "Affective attachment". The first ask if people agree with the policy that richer EU regions receive less and poorer regions receive more funding, which is the underlying principle of Cohesion Policy. This indicator measures the citizens' support to the values put forward by EU and we use it to proxy their attachment to EU and the European community:

- Support to redistribution: 1 (Agree); 2 (Disagree); 3 (D/K).

We consider whether the respondents voted in the last two EU parliamentary elections:

- Vote in EU parliamentary elections: 0 (Neither); 1 (Once); 2 (Both times).

We also consider control variables at the individual level, $\boldsymbol{Z}_{i j}$, including age, education, occupational and economic status. These are usually included in empirical applications. Contextual covariates, $\boldsymbol{Z}_{j}^{g}$, are introduced at the regional level. These include two variables measuring the economic situation in the region, such as, the level of GDP per inhabitant in Euro at 2014 as percentage of EU average and the unemployment rate for 20-64 years people at 2014. Regions that lag behind on economic development may have a less favorable attitude toward the EU but at the same time are the ones that 
receive more Structural Funds. Hence, we need to control for regions' wealth when assessing the role of Cohesion Policy. This is measured by the per capita amount of Structural Fund expenditures in the period 2007-13 that is mostly allocated to less developed regions and could reinforce the idea of solidarity and care for others within Europe, and the citizen's support to the EU (Osterloch, 2011; Capello and Perucca, 2019). However, its effect can be influenced by the local context of implementation of Cohesion Policy at regional level (Capello and Perucca, 2019). Here we include the absorption rate of the Structural Fund financial allocation at 2013 that could be considered as a proxy for the regions' efficiency in implementation of Cohesion Policy, and the European Index of Institutional Quality (EQI) at 2013 (normalized at 100).

\section{Discussion of results}

\subsection{Citizens' perception and identification with European Union}

We apply the IdentEU model to study and classify the citizens' level of identification with EU and to understand to what extent EU citizens identify with the EU project at individual and regional level ${ }^{7}$. We identify six different clusters (latent classes), which represent citizens with different patterns of identification with the EU project. A set of probabilities describes how each cluster is related to the indicators. We can characterize and name each cluster by analyzing the response probabilities for each indicator as they show the characteristics of each cluster and highlight similarities and differences ${ }^{8}$. They sum to 1 within each class and are reported in Table 1.

Looking at the response (marginal) probabilities for each indicator, we clearly identify three clusters (1,3 and 4) of individuals that strongly identify with the EU, that include about $60 \%$ of citizens, and three clusters $(2,5$ and 6$)$ of individuals that do not considerably identify with Europe, which account for about $40 \%$. In fact, individuals in Clusters 1,3 , and 4 , have a high probability ( 0.9 or more) of strongly identifying with the EU as they identify with their own country and even more and they evaluate the EU membership of their country as a good thing with high probability (more than $72 \%$ ). On the contrary, individuals in Clusters 2, 5 and 6 have almost zero chance to answer they identify

\footnotetext{
${ }^{7}$ Empirical analysis in sections 4.1 and 4.2 attains to the whole sample of individuals and regions. The analysis in section 4.3 focus on nine case-study regions: descriptive statistics are estimated on the subsample including observations from the nine regions while other results are estimates from the overall model.

${ }^{8}$ Probabilities are functions of different set of parameters. Significant differences among cluster for each indicator can be assessed by Wald statistics which tests the restriction that a specific set of parameter estimates equals zero. A nonsignificant p-value associated with this Wald statistic means that the indicator does not discriminate between the clusters in a statistically significant way. Similarly, we can test significant different effects among clusters and regional groups for each covariate. All tests show significant effects. We do not show results here for sake of brevity (the model contains 190 parameters) but they are available on request from the authors.
} 
strongly with the EU and they negatively consider the EU membership of their country. However, there are differences among clusters within both groups when considering trust in the EU institutions, such as perception of their effectiveness and corruption. We describe the six clusters in relation with each other, as follows.

Cluster 1 - "Disappointed pro-EU" (about 27\% of individuals). Despite strongly identifying with Europe and appreciating the EU membership, people in Cluster 1 consider negatively the effectiveness of the EU in solving the problems in their region (less or as effective as their national governing institutions). They perceive a high level of corruption in EU institutions, equal or more widespread than in national institutions. They are aware of and agree with the idea of redistribution implied by the Cohesion Policy, though to a smaller extent than clusters 3 and 4. In contrast, Clusters 2, 5 and 6 include people that weakly identify with Europe and identify stronger with their own country.

Cluster 2 - "EU Deniers" (20\% of individuals). It emerges as the group characterized by the mostly negative attitude toward many dimensions considered by the indicators. They believe the EU is not effective in solving problems of their region (chance 90\%) and less effective than national government. They think that corruption is widespread in EU and national institutions (chance 86\%) and they think that the EU membership is bad (chance 74\%). Nevertheless, the majority still agrees with the policy of sustaining the poorest regions but the proportion of individuals who disagree with this policy is the highest across clusters (36\%).

Cluster 3 - "Confident Europeans" (17\% of individuals). People in Cluster 3 perceive a low level of corruption in EU, even in comparison to their national government. However, they negatively perceive the effectiveness of EU in solving problems, especially in comparison to national government.

Cluster 4 - "Wary pro-Europe" (15\% of individuals). On the contrary, people in Cluster 4 consider the actions of the EU in solving problems quite effective, even more effective than the action of their own country. Nevertheless, their trust in the EU institutions is low because they perceive a high level of corruption, even in their national governing institutions. Yet, people in both clusters strongly agree with the values of solidarity represented by the Cohesion Policy, and the chance that they are aware of regional policies is quite high.

Cluster 5 - "Disaffected Europeans" (11\% of individuals). For clusters 5 and 6 the identification with Europe is somewhat stronger and people are less likely to consider the EU membership as a bad thing. Moreover, they agree with the policy of supporting the poorest region but a larger proportion of people than other clusters do not agree. Instead, they show a very different attitude regarding the 
two issues of effectiveness and corruption. People in Cluster 5 likely trust the EU because they do not perceive a high level of corruption in comparison to the situation in their country. However, they negatively evaluate the effectiveness of the EU in solving problems in their region (with $80 \%$ chance) and consider national government as more effective.

Cluster 6 - "Wary cons Europeans" (10\% of individuals). Individuals in Cluster 6 positively evaluate the capacity of EU institutions in solving problems, especially in comparison to the national institutions. However, the chance that people perceive widespread corruption is about $50 \%$.

Regarding other dimensions related to the identification with the EU project, we see that clusters' composition is not largely affected by citizens' participation in the last two elections. Yet, "EU Deniers" (Cluster 2) and "Disaffected Europeans" (Cluster 5) have the highest chance (40\%) of not voting in both occasions, while this probability is lower in clusters 3 and 4 . Awareness of Regional/Cohesion policy is rather high but heterogeneous across clusters. In particular, it is lower in clusters 2, 5 or 6 than Cluster 4 or 3 . 
Table 1. Profile table at individual level: cluster size and cluster specific marginal probabilities

\begin{tabular}{|c|c|c|c|c|c|c|}
\hline & $\begin{array}{r}\text { Cluster 1 } \\
\text { Disappointed } \\
\text { pro-Europe } \\
\end{array}$ & $\begin{array}{r}\text { Cluster } 2 \\
E U \\
\text { Deniers } \\
\end{array}$ & $\begin{array}{r}\text { Cluster } 3 \\
\text { Confident } \\
\text { Europeans } \\
\end{array}$ & $\begin{array}{r}\text { Cluster } 4 \\
\text { Wary pro- } \\
\text { Europe } \\
\end{array}$ & $\begin{array}{r}\text { Cluster 5 } \\
\text { Disaffected } \\
\text { Europeans } \\
\end{array}$ & $\begin{array}{r}\text { Cluster } 6 \\
\text { Wary Cons- } \\
\text { Europe } \\
\end{array}$ \\
\hline Cluster Size & 0.2727 & 0.1972 & 0.1752 & 0.1495 & 0.1056 & 0.0999 \\
\hline \multicolumn{7}{|l|}{ Indicators } \\
\hline \multicolumn{7}{|c|}{ How strongly identify with Europe } \\
\hline Not much strongly & 0 & 0.4612 & 0.0362 & 0 & 0.2704 & 0.2857 \\
\hline Somewhat & 0.0995 & 0.5387 & 0.0681 & 0.0726 & 0.7293 & 0.7142 \\
\hline Strongly & 0.9005 & 0 & 0.8957 & 0.9273 & 0.0003 & 0.0001 \\
\hline \multicolumn{7}{|c|}{ Europe vs Country identification } \\
\hline Less & 0 & 0.6849 & 0 & 0 & 0.6716 & 0.7187 \\
\hline Equal & 0.8595 & 0.2942 & 0.8271 & 0.8557 & 0.3193 & 0.2573 \\
\hline More & 0.1405 & 0.0209 & 0.1729 & 0.1443 & 0.0091 & 0.0241 \\
\hline \multicolumn{7}{|c|}{ Effectiveness in solving problems } \\
\hline Not so Effective & 0.7413 & 0.9007 & 0.3498 & 0.0001 & 0.7966 & 0.0001 \\
\hline Somewhat effective & 0.2587 & 0.0957 & 0.4656 & 0.6501 & 0.2033 & 0.7156 \\
\hline Very effective & 0 & 0.0036 & 0.1845 & 0.3498 & 0 & 0.2843 \\
\hline \multicolumn{7}{|l|}{ EU vs National effectiveness } \\
\hline Less & 0.3386 & 0.3069 & 0.1694 & 0.0071 & 0.3654 & 0.0085 \\
\hline Equal & 0.6614 & 0.6931 & 0.5138 & 0.4274 & 0.6346 & 0.4143 \\
\hline More & 0 & 0 & 0.3168 & 0.5655 & 0 & 0.5772 \\
\hline \multicolumn{7}{|l|}{ Corruption in $E U$} \\
\hline Low & 0.082 & 0.0006 & 0.3341 & 0.0846 & 0.2302 & 0.1165 \\
\hline Medium & 0.3462 & 0.1368 & 0.6659 & 0.2663 & 0.7697 & 0.3861 \\
\hline High & 0.5718 & 0.8625 & 0 & 0.6491 & 0.0001 & 0.4974 \\
\hline \multicolumn{7}{|l|}{ EU vs National Corruption } \\
\hline Less & 0.0001 & 0 & 0.9998 & 0 & 0.5253 & 0.255 \\
\hline Equal & 0.7792 & 0.729 & 0.0002 & 0.8458 & 0.4226 & 0.6135 \\
\hline More & 0.2207 & 0.2709 & 0 & 0.1542 & 0.0522 & 0.1315 \\
\hline \multicolumn{7}{|l|}{ Vote } \\
\hline Neither & 0.2869 & 0.3916 & 0.2533 & 0.2642 & 0.3904 & 0.3718 \\
\hline Once & 0.1481 & 0.1433 & 0.168 & 0.1755 & 0.1924 & 0.1797 \\
\hline Both times & 0.5468 & 0.4456 & 0.5561 & 0.5423 & 0.3945 & 0.4181 \\
\hline (d/k-refused) & 0.0182 & 0.0195 & 0.0227 & 0.018 & 0.0226 & 0.0304 \\
\hline \multicolumn{7}{|l|}{ Support to Cohesion policy } \\
\hline Agree & 0.8291 & 0.6238 & 0.9022 & 0.8845 & 0.7556 & 0.8007 \\
\hline Disagree & 0.1576 & 0.3642 & 0.087 & 0.1061 & 0.2271 & 0.1832 \\
\hline$d / k$ & 0.0133 & 0.012 & 0.0108 & 0.0094 & 0.0173 & 0.0162 \\
\hline \multicolumn{7}{|l|}{ EU membership } \\
\hline Bad thing & 0.2751 & 0.7464 & 0.1743 & 0.1727 & 0.4786 & 0.4718 \\
\hline Good Thing & 0.7249 & 0.2536 & 0.8257 & 0.8273 & 0.5214 & 0.5282 \\
\hline \multicolumn{7}{|c|}{ Awareness of Cohesion policy } \\
\hline None & 0.1819 & 0.2664 & 0.1019 & 0.1141 & 0.2578 & 0.2082 \\
\hline only local project & 0.0863 & 0.1053 & 0.1291 & 0.1023 & 0.1078 & 0.1236 \\
\hline Cohesion/regional policies & 0.7318 & 0.6283 & 0.769 & 0.7836 & 0.6344 & 0.6683 \\
\hline
\end{tabular}




\subsection{Role of individual characteristics and of the regional context}

Membership to latent classes can be related to individual demographic or socio-economic characteristics. The probability for an individual to belong to a specific latent class has been modelled to depend on the age of individuals (considered as continuous variable), the level of education, and the income level. Other variables also are considered for describing the clusters ${ }^{9}$. Table 2 shows the probability to be classified in each cluster for each specific range of covariate and the comparison to the overall distribution (unconditional probabilities, reported in the first row).

Comparing the distributions at each age class ${ }^{10}$ to the marginal distribution by cluster, younger individuals are underrepresented in Cluster 1 and overrepresented in Cluster 3 (which is the cluster most favorable to Europe and EU). In Clusters 5 and Cluster 6, however, these differences are rather small. Thus, we conclude that age has a marginal influence on identification.

A clearer pattern emerges with regards to education. Individuals with a tertiary education have a slightly higher probability of being allocated to clusters with a higher level of identification and positive attitude toward EU institutions (Clusters 3 and 4). In contrast, people with the lowest level of education are overrepresented in Cluster 2, which comprises of citizens that do not identify with the EU and are the most critical towards the European institutions.

A similar pattern emerges for income levels. Individuals with high income are more likely to be included in Cluster 3 and Cluster 1 and less likely to be included in Cluster 2. Individuals with low income are more likely being classified in Cluster 2 and less in Clusters 3 and 4. Unemployed people are over-represented in Cluster 2 (i.e. the most EU skeptical and unsatisfied) and under-represented in Clusters 3, 4 and 1. Students and trainees are more represented in Clusters 3, 4 and 5, and less in Clusters 2 and 1 . We cannot identify a clear divide by gender. People that are unsatisfied with the economic situation are over-represented in Cluster 2 and underrepresented in Cluster 4 and 1, while the contrary holds for satisfied people. In conclusion, it is possible to identify the influence of some individual characteristics on the level of identification and citizens' attitudes toward the EU, even if such effects are not very large in many cases.

\footnotetext{
${ }^{9}$ Gender, occupational status and satisfaction with the economic situation are used to describe the clusters. Nevertheless, they are not included in the final model and do not concur directly to determine the membership's probabilities.

${ }^{10}$ The variable age is introduced in the model as a continuous variable. The probabilities are calculated for age classes automatically determined dividing the sample values in five groups.
} 
Table 2. Conditional probabilities of cluster membership for individual level covariates

\begin{tabular}{|c|c|c|c|c|c|c|}
\hline & $\begin{array}{r}\text { Cluster1 } \\
\text { Disappointed } \\
\text { pro-Europe } \\
\end{array}$ & $\begin{array}{r}\text { Cluster2 } \\
\text { EU Deniers }\end{array}$ & $\begin{array}{r}\text { Cluster3 } \\
\text { Confident } \\
\text { Europeans } \\
\end{array}$ & $\begin{array}{r}\text { Cluster4 } \\
\text { Wary pro- } \\
\text { Europe } \\
\end{array}$ & $\begin{array}{r}\text { Cluster5 } \\
\text { Disaffected } \\
\text { Europeans } \\
\end{array}$ & $\begin{array}{r}\text { Cluster6 } \\
\text { Wary Cons- } \\
\text { Europe } \\
\end{array}$ \\
\hline Overall & 0.273 & 0.197 & 0.175 & 0.150 & 0.106 & 0.100 \\
\hline \multicolumn{7}{|l|}{ Age (years) } \\
\hline $18-33$ & 0.231 & 0.178 & 0.189 & 0.150 & 0.127 & 0.125 \\
\hline $33-44$ & 0.262 & 0.190 & 0.195 & 0.139 & 0.107 & 0.107 \\
\hline $45-55$ & 0.288 & 0.208 & 0.166 & 0.143 & 0.103 & 0.092 \\
\hline $56-65$ & 0.278 & 0.209 & 0.166 & 0.159 & 0.101 & 0.087 \\
\hline More than 65 & 0.303 & 0.202 & 0.161 & 0.156 & 0.091 & 0.088 \\
\hline \multicolumn{7}{|l|}{ Education } \\
\hline $\begin{array}{l}\text { Primary and lower } \\
\text { secondary }\end{array}$ & 0.261 & 0.245 & 0.116 & 0.131 & 0.124 & 0.123 \\
\hline High secondary & 0.251 & 0.213 & 0.177 & 0.146 & 0.105 & 0.109 \\
\hline Degree and $\mathrm{PhD}$ & 0.297 & 0.161 & 0.202 & 0.161 & 0.098 & 0.081 \\
\hline \multicolumn{7}{|l|}{ Income } \\
\hline Low & 0.245 & 0.217 & 0.156 & 0.142 & 0.113 & 0.127 \\
\hline Medium & 0.249 & 0.215 & 0.166 & 0.160 & 0.110 & 0.101 \\
\hline High & 0.312 & 0.170 & 0.192 & 0.149 & 0.096 & 0.081 \\
\hline $\mathrm{DK} / \mathrm{R}$ & 0.285 & 0.180 & 0.209 & 0.141 & 0.105 & 0.080 \\
\hline \multicolumn{7}{|c|}{ Not Included in the Model } \\
\hline \multicolumn{7}{|l|}{ Gender } \\
\hline Male & 0.263 & 0.2049 & 0.1732 & 0.1517 & 0.1069 & 0.1002 \\
\hline Female & 0.2822 & 0.1896 & 0.1772 & 0.1473 & 0.1042 & 0.0995 \\
\hline \multicolumn{7}{|l|}{ Occupation } \\
\hline Employed & 0.2709 & 0.1912 & 0.1827 & 0.1457 & 0.1071 & 0.1023 \\
\hline Unemployed & 0.2314 & 0.2544 & 0.1346 & 0.1386 & 0.1147 & 0.1263 \\
\hline $\begin{array}{l}\text { Housewife, } \\
\text { Pensioner, Retired, } \\
\text { Other }\end{array}$ & 0.2878 & 0.2046 & 0.1646 & 0.1555 & 0.097 & 0.0905 \\
\hline Student, Trainee & 0.2397 & 0.1352 & 0.2159 & 0.1695 & 0.1383 & 0.1014 \\
\hline \multicolumn{7}{|c|}{ Satisfied with economic situation } \\
\hline Not satisfied & 0.2375 & 0.238 & 0.1745 & 0.1327 & 0.1068 & 0.1105 \\
\hline Satisfied & 0.2997 & 0.1658 & 0.1758 & 0.1623 & 0.1046 & 0.0917 \\
\hline
\end{tabular}

We replicate the analysis by adding the context covariates at regional level (Table 3). The wealth of the region where citizens live impacts on the results. Cluster 1 is over-represented in regions with high GDP per capita and low unemployment. Cluster 3 and 4 are overrepresented in the poorest regions and underrepresented in regions with high levels of GDP per capita and low level of unemployment. Cluster 2, i.e. the most adverse to EU project, is underrepresented in the poorest regions and overrepresented in richest regions. Cluster 6 is more likely represented in poor regions with high unemployment, while Cluster 5 is underrepresented in the same regions.

Considering the effect of the EU funds' absorption rate as an approximation of efficiency in implementing Cohesion Policy, we cannot identify a clear pattern. People living in higher efficiency 
regions are most likely assigned to Cluster 1 and somewhat to Clusters 4 and 6, while people living in regions with low values (less efficient) are more likely assigned to Cluster 3.

Table 3. Conditional probabilities of cluster membership for contextual level covariates

\begin{tabular}{|c|c|c|c|c|c|c|}
\hline & $\begin{array}{r}\text { Cluster1 } \\
\text { Disappointed } \\
\text { pro-Europe }\end{array}$ & $\begin{array}{r}\text { Cluster2 } \\
E U \text { Deniers }\end{array}$ & $\begin{array}{r}\text { Cluster3 } \\
\text { Confident } \\
\text { Europeans } \\
\end{array}$ & $\begin{array}{r}\text { Cluster4 } \\
\text { Wary pro- } \\
\text { Europe } \\
\end{array}$ & $\begin{array}{r}\text { Cluster5 } \\
\text { Disaffected } \\
\text { Europeans } \\
\end{array}$ & $\begin{array}{r}\text { Cluster6 } \\
\text { Wary Cons- } \\
\text { Europe } \\
\end{array}$ \\
\hline Overall & 0.2727 & 0.1972 & 0.1752 & 0.1495 & 0.1056 & 0.0999 \\
\hline \multicolumn{7}{|c|}{ GDP pc (\% of EU average) } \\
\hline $0-37$ & 0.194 & 0.120 & 0.302 & 0.169 & 0.074 & 0.141 \\
\hline $37-59$ & 0.248 & 0.182 & 0.191 & 0.174 & 0.101 & 0.105 \\
\hline $59-97$ & 0.248 & 0.210 & 0.175 & 0.149 & 0.103 & 0.116 \\
\hline $97-118$ & 0.302 & 0.273 & 0.118 & 0.121 & 0.122 & 0.065 \\
\hline More than 118 & 0.375 & 0.203 & 0.088 & 0.133 & 0.129 & 0.073 \\
\hline \multicolumn{7}{|c|}{ Unemployment rate (\%) } \\
\hline $0-5.5$ & 0.350 & 0.197 & 0.126 & 0.136 & 0.112 & 0.079 \\
\hline $5.5-8$ & 0.285 & 0.229 & 0.134 & 0.127 & 0.136 & 0.090 \\
\hline $8-9.5$ & 0.281 & 0.187 & 0.191 & 0.156 & 0.097 & 0.088 \\
\hline $9.5-14$ & 0.240 & 0.193 & 0.219 & 0.130 & 0.102 & 0.117 \\
\hline more than 14 & 0.205 & 0.179 & 0.211 & 0.199 & 0.080 & 0.127 \\
\hline \multicolumn{7}{|l|}{ Absorption rate } \\
\hline $0-0.5$ & 0.224 & 0.188 & 0.234 & 0.133 & 0.097 & 0.124 \\
\hline $0.5-0.6$ & 0.272 & 0.221 & 0.164 & 0.166 & 0.100 & 0.077 \\
\hline $0.6-0.65$ & 0.315 & 0.195 & 0.175 & 0.135 & 0.103 & 0.076 \\
\hline $0.65-0.78$ & 0.316 & 0.189 & 0.146 & 0.145 & 0.113 & 0.091 \\
\hline more than 0.78 & 0.232 & 0.194 & 0.158 & 0.170 & 0.115 & 0.132 \\
\hline \multicolumn{7}{|c|}{ SF per capita (Euros) } \\
\hline $0-108$ & 0.314 & 0.232 & 0.120 & 0.125 & 0.126 & 0.083 \\
\hline $108-215$ & 0.310 & 0.248 & 0.118 & 0.126 & 0.121 & 0.077 \\
\hline $215-935$ & 0.239 & 0.160 & 0.228 & 0.151 & 0.100 & 0.123 \\
\hline $935-2059$ & 0.267 & 0.166 & 0.203 & 0.161 & 0.083 & 0.119 \\
\hline More than 2059 & 0.235 & 0.180 & 0.207 & 0.183 & 0.097 & 0.099 \\
\hline \multicolumn{7}{|c|}{ Not included in the model } \\
\hline \multicolumn{7}{|c|}{ Quality of institution Index (min $0, \max 100)$} \\
\hline $0-36$ & 0.228 & 0.192 & 0.243 & 0.126 & 0.092 & 0.119 \\
\hline $36-42$ & 0.250 & 0.161 & 0.232 & 0.187 & 0.078 & 0.092 \\
\hline $42-56$ & 0.216 & 0.181 & 0.204 & 0.171 & 0.099 & 0.128 \\
\hline $56-66$ & 0.318 & 0.228 & 0.119 & 0.132 & 0.125 & 0.078 \\
\hline More than 66 & 0.353 & 0.223 & 0.077 & 0.131 & 0.133 & 0.083 \\
\hline
\end{tabular}

The amount of Structural Funds received by the region has some influence on identification. People living in regions that received large funding (typically regions targeted as "Convergence Objective") are more likely classified in Clusters 3 and 4 (i.e. those showing strong identification and positive attitude toward EU). In contrast, people living in regions where EU funds are low are more likely to 
be in Clusters 1 (they strongly identify but they do not trust EU), in Cluster 2 (do not identify and do not trust EU), and Cluster 5 (they identify more with their country, and do not evaluate positively the effectiveness of EU in solving problems).

Finally, people living in regions with high institutional quality have a higher chance to be classified in Cluster 1, 2 and 5. Despite the level of identification differs among these clusters, they share the perception of high level of corruption in EU institutions and a greater trust in national governments. On the contrary, people living in regions with low or medium level of institutional quality are more likely classified in Clusters 3 and 4, both with a high level of identification (even if individuals in Cluster 4 are somewhat critics about EU corruption) and have a higher probability to be classified in Cluster 6 (lower level of identification but trust EU institutions regarding corruption).

\subsection{Focus on the nine case-study regions}

The results of the model help to describe and compare the structures of citizens' identification across different regions and provide a classification of the regions in groups identifying different regional typologies. Overall results at regional level are discussed in Brasili et al. (forthcoming), here we present an in depth analysis of the results regarding nine EU case-study regions. These regions have been selected for their ability to represent the complex and heterogeneous reality of EU Cohesion Policy performance and its multidimensional determinants in terms of socio-economic, political and demographic characteristics. The choice is balanced between regions targeted for the "Competitiveness and Employment" and for the "Convergence" objectives. These are two regions from Italy (Emilia-Romagna and Calabria), two regions from Poland (Dolnoslaskie and WarminskoMazurskie), Burgenland (Austria), Extremadura (Spain), Essex (UK), Norra Mellansverige (Sweden), and Sud-Est Romania.

Economic performance. The regional case studies show a great variability in the economic performance (Table 4) ${ }^{11}$. With regards to GDP per capita, three regions, Emilia-Romagna, Norra Mellansverige and Essex, are in the top 25\% percentile of the distribution of the regions in the EU and show an unemployment rate below 8\%. The Romanian and Polish regions' GDP per capita in 2014 were below the $50 \%$ of the EU average. Calabria and Extremadura's were below the $60 \%$ of the

\footnotetext{
${ }^{11}$ A detailed socio-economic analysis of the case-study regions is provided in PERCEIVE - D1.1 "Report on Regional Case-Studies" (Aiello et al., 2017)
} 
EU average, while the GDP of the Burgenland was very close to the European average. The unemployment rate ranges from $4.5 \%$ in Essex up to 29\% in Extremadura.

Table 4. Case study regions, socio-economic characteristics

\begin{tabular}{|c|c|c|c|c|c|c|}
\hline Region & Objective & GDP $^{a}$ & Unemployment $^{b}$ & EQI & $\begin{array}{r}\text { Absorption } \\
\text { rate }^{c}\end{array}$ & $\begin{array}{r}\text { Structural } \\
\text { Funds } \\
\text { per capita }^{d}\end{array}$ \\
\hline RO22 -Sud-Est & CONV & 25 & 10,00 & 13,37 & $32,14 \%$ & 934,09 \\
\hline PL51 - Dolnoslaskie & CONV & 43 & 9,10 & 35,49 & $64,70 \%$ & $1.741,62$ \\
\hline PL62 - Warminsko-Mazurskie & CONV & 28 & 9,60 & 43,99 & $66,33 \%$ & $2.058,60$ \\
\hline ES43 - Extremadura & CONV & 56 & 29,30 & 54,35 & $116,02 \%$ & $2.359,96$ \\
\hline AT11 - Burgenland & PH-OUT & 97 & 4,70 & 68,14 & $77,37 \%$ & 625,02 \\
\hline ITD5 - Emilia-Romagna & COMP & 118 & 8,20 & 31,77 & $44,44 \%$ & 107,78 \\
\hline ITF6 - Calabria & CONV & 59 & 23,10 & 17,85 & $50,24 \%$ & $1.491,24$ \\
\hline UKH3 - Essex & COMP & 117 & 4,50 & 65,54 & $59,84 \%$ & 67,68 \\
\hline SE31 - Norra Mellansverige & COMP & 139 & 7,20 & 74,24 & $79,09 \%$ & 436,51 \\
\hline
\end{tabular}

a. Euro per inhabitant in percentage of the EU average, 2014

b. Unemployment rate: population $20-64$ years, 2014

c. Ratio of SF expenditures up to 2013 to the SF allocation in the $2007-2013$ period

d. Total SF expenditures in years 2007-13 divided by the average population in the period 2007-13

Cohesion Policy's performance. Within the two variables concerning the Cohesion Policy's performance, the per-capita amount of Structural Funds was greater in Extremadura $(€ 2.359)$, in the two Polish regions $(€ 2.058, € 1.741)$, and in Calabria (€1.491). For the remaining regions, the values range from $€ 934$ in Sud-Est Romania to $€ 67$ in Essex. The absorption rate of Structural Funds, which we consider as a proxy for the efficiency of the implementation of Cohesion Policy, differs across regions, ranging from $116 \%$ in Extremadura (ES) ${ }^{12}$ to $32 \%$ in Sud-Est (RO).

Quality of institutions. Regions from Austria, the United Kingdom and Sweden reach the top positions of the EU by quality of institutions. Emilia-Romagna is one of the best performers in Italy, but it ranks rather low compared to some other EU regions. Among the Convergence Objective regions, Calabria has one of the lowest values of the index of institutional quality in Europe. Romania, among the countries with the lowest performance, has a high level of perceived corruption and the Sud-Est (RO) region does not differ from the national case. Poland's institutional quality is below the EU average: Dolnośląskie and Warmińsko-Mazurskie have both negative scores but they have the lowest and the best scores, respectively, of all the Polish regions. In contrast, Extremadura (ES)'s results are very similar to the EU average and slightly higher than the whole Spain.

\footnotetext{
${ }^{12}$ A value of absorption rate higher than $100 \%$ implies that total commitments are greater than the total initial Structural Fund allocation. In this way a region obtains more easily the $100 \%$ reimbursement of resources at the end of the program.
} 
The high regional variability in terms of macroeconomic context, institutional quality and Cohesion Policy's financial allocation is reflected in the heterogeneous picture that emerges when looking at the regions' levels of identification with the EU.

Table 5 shows the distribution of the main indicators used in the analysis in the case study region and in overall Europe. Considering overall EU, we notice that most citizens are aware of the existence of Cohesion Policy (70\%). More than 50\% strongly identify with the EU while only 15\% weakly identify. However, more than half of citizens (56\%) think the EU is not effective in solving problems faced by the regions. Only 13\% of citizens perceive a low level of corruption in EU institutions. However, more than $62 \%$ think that EU membership is a good thing and $80 \%$ agree with the redistribution policy.

Table 5. Distribution of responses for some indicators in the nine case study regions and overall Europe (percentages)

\begin{tabular}{|c|c|c|c|c|c|c|c|c|c|c|}
\hline & SE31 & AT11 & ES43 & PL51 & PL62 & RO22 & UKH3 & ITF6 & ITD5 & $\begin{array}{l}\text { Overall } \\
\text { Europe }\end{array}$ \\
\hline \multicolumn{11}{|l|}{ Awareness } \\
\hline None & 24.2 & 13.9 & 12.9 & 6.2 & 6.9 & 6.6 & 59.9 & 9.8 & 19.3 & 20.6 \\
\hline Only local project & 7.2 & 3.4 & 7.4 & 7.6 & 10.1 & 6.2 & 3.9 & 14.9 & 11.7 & 9.4 \\
\hline Cohesion Policy & 68.6 & 82.7 & 79.7 & 86.2 & 83.1 & 87.2 & 36.2 & 75.3 & 69.1 & 70.0 \\
\hline \multicolumn{11}{|c|}{ Identification with Europe } \\
\hline Not strongly & 12.8 & 16.0 & 12.9 & 6.9 & 10.3 & 7.8 & 28.4 & 21.4 & 16.2 & 15.5 \\
\hline Somewhat strongly & 34.2 & 31.0 & 28.9 & 23.7 & 24.7 & 25.9 & 19.6 & 37.8 & 37.8 & 31.5 \\
\hline Strongly & 53.0 & 53.0 & 58.2 & 69.4 & 65.0 & 66.3 & 52.0 & 40.8 & 46.0 & 53.0 \\
\hline \multicolumn{11}{|l|}{ Effectiveness of EU } \\
\hline Not so Effective & 62.3 & 57.7 & 27.2 & 48.3 & 48.4 & 12.1 & 68.3 & 77.9 & 70.4 & 56.0 \\
\hline Somewhat effective & 34.4 & 30.7 & 52.0 & 45.4 & 43.5 & 48.9 & 20.9 & 17.2 & 24.7 & 34.0 \\
\hline Very effective & 3.3 & 11.6 & 20.9 & 6.3 & 8.1 & 39.1 & 10.8 & 4.9 & 4.9 & 10.0 \\
\hline \multicolumn{11}{|l|}{ Corruption in EU } \\
\hline Low & 10.9 & 16.5 & 7.0 & 17.2 & 15.9 & 31.3 & 20.1 & 3.7 & 2.9 & 12.7 \\
\hline Medium & 51.8 & 42.2 & 31.4 & 43.8 & 40.7 & 35.1 & 41.8 & 36.0 & 35.5 & 40.5 \\
\hline High & 37.4 & 41.3 & 61.5 & 39.0 & 43.5 & 33.6 & 38.1 & 60.3 & 61.6 & 46.8 \\
\hline \multicolumn{11}{|l|}{ EU membership } \\
\hline Bad thing & 48.9 & 32.2 & 29.4 & 24.5 & 25.4 & 21.4 & 40.9 & 67.4 & 57.9 & 37.4 \\
\hline Good Thing & 51.1 & 67.8 & 70.7 & 75.5 & 74.6 & 78.6 & 59.2 & 32.7 & 42.1 & 62.6 \\
\hline \multicolumn{11}{|c|}{ Support to redistribution } \\
\hline Agree & 82.0 & 71.5 & 89.7 & 88.2 & 85.7 & 91.6 & 73.8 & 76.0 & 73.2 & 79.1 \\
\hline Not agree & 15.1 & 28.2 & 10.1 & 8.4 & 11.4 & 8.4 & 26.0 & 24.0 & 26.4 & 19.8 \\
\hline $\mathrm{D} / \mathrm{K}$ & 2.9 & 0.4 & 0.2 & 3.4 & 3.0 & 0.0 & 0.2 & 0.0 & 0.3 & 1.2 \\
\hline
\end{tabular}

Note: Survey estimates. Representative samples for each of the nine case-study regions are provided by the PERCEIVE survey 
The three regions from Poland and Romania have a share of citizens that identify strongly with the EU (higher than the EU average), while the two Italian regions rank the lowest. In particular, the lowest share of people who do not strongly identify is in Essex (UK), followed by Calabria (IT). The two Italian regions also have a larger share of people that consider the EU membership as a bad thing, unlike of Eastern European regions and of Extremadura (ES). Norra Mellansverige (SE) also has a small share of people who are satisfied with EU membership. Regions from Italy and Spain show the worst perception of corruption in EU institutions, while people from other regions have a more favorable view, especially citizens from Romania and UK. However, in most of the regions analyzed, people think the EU is not very effective in solving the problems facing their regions (with the exception of Extremadura and Sud-Est Romania).

Then, we analyze the composition of clusters within each region to identify whether different structures of citizens' identification can be identified in the nine case-study regions. Posterior clusters' membership probabilities are displayed in Table 6 and account for the people's responses to the survey questions. The chance for a citizen to be classified into cluster 2 (EU Deniers) is the highest in Essex and in the two Italian regions, followed by the regions from Sweden and Austria. These regions also have smaller probabilities of being classified in clusters 3 and 4. On the contrary, in the two Polish regions, in Extremadura, and especially in Sud-Est Romania there is the highest chance that people belong to Clusters 3 (Confident Europeans) and 4 (Wary pro-Europe), hence identify much strongly and trust EU institutions. The presence of Cluster 1 (Disappointed pro- Europe), which includes people that strongly identify with Europe but criticize the level of corruption and effectiveness of EU institution, is significant in each region. Nevertheless, its weight emerges in the regions from Sweden, Italy, Austria, and is the lowest in Extremadura. Cluster 5 (Disaffected Europeans) and Cluster 6 (Wary Cons-Europe), which include citizens with a moderate identification with EU and critical about EU effectiveness (cluster 5) and corruption (cluster 6), show a regionspecific pattern. Cluster 5 has an overrepresentation of richest regions (Calabria being the only exception), while Cluster 6 includes Extremadura and Sud-Est Romania. 
Table 6. Posterior probabilities of cluster membership, by case study regions

\begin{tabular}{lrrrrrrr}
\hline Case-study regions & Cluster 1 & Cluster 2 & Cluster 3 & Cluster 4 & Cluster 5 & Cluster 6 & Totale \\
\hline SE31 - Norra Mellansverige & 0.390 & 0.232 & 0.061 & 0.102 & 0.150 & 0.064 & 1 \\
AT11 - Burgenland & 0.312 & 0.190 & 0.113 & 0.144 & 0.127 & 0.114 & 1 \\
ES43 - Extremadura & 0.176 & 0.135 & 0.220 & 0.242 & 0.063 & 0.164 & 1 \\
PL51 - Dolnoslaskie & 0.255 & 0.128 & 0.290 & 0.183 & 0.064 & 0.080 & 1 \\
PL62 - Warminsko-Mazurskie & 0.242 & 0.144 & 0.246 & 0.202 & 0.075 & 0.091 & 1 \\
RO22 -Sud-Est & 0.051 & 0.040 & 0.500 & 0.163 & 0.048 & 0.197 & 1 \\
UKH3 - Essex & 0.268 & 0.322 & 0.109 & 0.117 & 0.126 & 0.057 & 1 \\
ITF6 - Calabria & 0.338 & 0.312 & 0.092 & 0.077 & 0.130 & 0.051 & 1 \\
ITD5 - Emilia-Romagna & 0.343 & 0.286 & 0.113 & 0.103 & 0.108 & 0.047 & 1 \\
\hline Overall & $\mathbf{0 . 2 7 2}$ & $\mathbf{0 . 1 9 8}$ & $\mathbf{0 . 1 7 8}$ & $\mathbf{0 . 1 4 8}$ & $\mathbf{0 . 1 0 5}$ & $\mathbf{0 . 0 9 9}$ & $\mathbf{1}$ \\
\hline
\end{tabular}

Finally, IdentEU allows us to identify latent groups of regions according to their level of identification with the EU project. Indeed, the model accounts for the hierarchical (nested) nature of the data, where individuals are nested into regions. This means that we can classify regions into a smaller number of latent classes (groups), which identify latent types of regional structures of citizens' identification. We identify four groups of regions based on the same dimensions described at individual level, where each region can be allocated (Table 7).

Four regions are classified within Group 2 (High EU identification) that includes regions where people identify with the EU and trust and appreciate EU institutions. They have the highest chance of strongly identifying with Europe, of considering the EU membership a good thing, and of considering EU institutions as effective in solving problems. They perceive a lower level of corruption in the EU and show the highest support to the redistribution policy toward the poorest regions. These four regions, located in Romania, Poland and Spain, share a lower level of quality of institutions than the EU average and are among the highest beneficiaries of the Structural Funds, along with Italy's Calabria.

Table 7. Ranking of the case study regions according to their level of identification

\begin{tabular}{llrr}
\hline Region & Objective & $\begin{array}{r}\text { Group } \\
\text { Classification }\end{array}$ & Name \\
\hline RO22 -Sud-Est & Convergence & 2 & High EU identification \\
PL51 - Dolnoslaskie & Convergence & 2 & High EU identification \\
PL62 - Warminsko-Mazurskie & Convergence & 2 & High EU identification \\
ES43 - Extremadura & Convergence & 2 & High EU identification \\
AT11 - Burgenland & Phasing-out & 3 & Medium-high EU identification - Critics \\
ITD5 - Emilia-Romagna & Competitiveness & 4 & Low EU identification - Skeptical \\
ITF6 - Calabria & Convergence & 4 & Low EU identification - Skeptical \\
UKH3 - Essex & Competitiveness & 1 & Lower EU identification \\
SE31 - Norra Mellansverige & Competitiveness & 1 & Lower EU identification \\
\hline
\end{tabular}


The only case-study region that belongs to Group 3 (Medium-high Identification - Critics) is Burgenland. Regions in Group 3 show a relatively high chance of people strongly identifying with Europe, agreeing with the EU financial support to poorest regions, and perceiving the EU membership as a good thing. However, their citizens are concerned with corruption of EU institutions and think the EU is not effective in facing their region' needs. Compared to Group 2, many people are not aware of any EU financed policy.

Essex and Norra-Mellansverige belong to the group that includes the highest number of European regions, Group 1 (Lower EU identification). These two regions are among the richest of the sample and feature a high level of institutional quality. Yet their citizens weakly identify with the EU and do not consider the EU able of tackling the challenges faced by their region. They also think that EU institutions are more corrupt than their national institutions and, even though they aware of and appreciate Cohesion Policy, they do not think that the EU membership brings benefits to their country.

Both Italian regions, Emilia-Romagna and Calabria, are classified into Cluster 4 (Low EU identification - Skeptical). Despite a higher knowledge of the Cohesion Policy, their citizens are negative about EU membership and weakly identify with Europe. They also consider the EU as corrupt as their national institutions and not effective in solving their problems. Regardless of the differences in the regional social and economic contexts, citizens of these two Italian regions share a common mistrust towards institutions, both at the national and EU level, and have a negative consideration of Italy's EU membership. In this regard, the economic crisis, which hit Italy very hard, has played a relevant role to increase Italian citizens' mistrust in the EU project (Serricchio et al., 2013; Braun and Tausendpfund, 2014).

\section{Conclusions}

In this paper we propose an empirical analysis of perception and identification of EU citizens with the EU project, focusing on the regional and individual level. We identify six clusters of respondent types at the individual level: three of them (including about $60 \%$ of citizens) include individuals who strongly identify with the European project, whereas the remaining clusters include individuals who identify weakly with the European project. However, the clusters are heterogeneous along other dimensions: national vs EU identification, the evaluation of the EU membership and its effectiveness, the level of citizens' awareness of the existence of the Cohesion Policy and the agreement with its solidarity value, trust in EU institutions and the perceived level of corruption. 
Among the individual socio-economic characteristics, education and income influence the pattern of identification. More skilled and wealthier people show higher level of identification and positive attitude toward EU institutions (i.e. Clusters 3, 4 and 1) more frequently than citizens with low level of education and income.

Dissatisfaction with the EU often involves specific institutional aspects such as perceived corruption and efficacy in solving the problems faced by citizens in their regions. Citizens that weakly identify with the EU project and negatively evaluate the EU membership of their countries, include those that paid the highest (negative) consequences of the last financial and economic crisis. While the efficiency in implementing of EU Cohesion Policy (absorption rate) doesn't show a clear influencing pattern (apart for Clusters 1 and 3 in a opposite way), the amount of Structural Fund received by the region shows some influence. Indeed, people living in net beneficiary regions (i.e. "Convergence Objective" regions) are more likely have a stronger identification and positive attitude toward EU. Thus, the Cohesion Policy played a role in fostering citizens' identification and appreciation toward EU where the interventions funded by Structural Funds were more visible.

With regards to the assessment of specific regional patterns, the nine case-study regions are classified into one of the four groups identified by the model. They show a great variability in economic performance and are targeted differently by Cohesion Policy objectives and funding. Regions from Eastern Europe (the three from Poland and Romania, the last accessing the EU) and Extremadura are characterized by higher level of identification with the EU project and trust more the EU institution than the national ones. In contrast, regions from the UK, Sweden, Austria and Italy show a lower level of trust towards the EU and its institutions, and weak identification with EU. Regions from UK, Sweden and Austria trust more their national institutions and have the highest level of quality of institution within the case study regions. The two Italian case study regions are largely disaffected by both national and European institutions. Italian results have been influenced, and even reinforced, by the inability of national and EU institutions to manage the effects of the last economic crisis. All these regions, however, share the same view about the capacity of EU of tackling the problems and needs faced by their regions.

In conclusion, we find that the main drivers of citizens and regions' identification with the EU project can be identified as: the trust in EU institutions, the effectiveness of EU Cohesion Policy and spending, and the level of perceived corruption at the national and EU level. Our results suggest that 
in order to regain EU citizens' trust in the EU project and its implementation in the EU regions, EU institutions should focus less on the overall amount of money spent. Instead, the focus should be placed more on the welfare dimension and social impact of the EU projects funded by the Cohesion Policy and on the quality of both local and EU governance.

\section{Supplemental material}

The research data underlying this manuscript are available in AMS Acta Institutional Research Repository (http://doi.org/10.6092/unibo/amsacta/6226). 


\section{References}

Aiello, V., Brasili C., Calia P., Monasterolo I. (2018), Report on the probabilistic model of estimation of citizens' identification with the EU project and ranking of the case study regions, PERCEIVE Deliverable 2.4, PERCEIVE project (GA nr. 693529), DOI:10.6092/unibo/amsacta/6113

Aiello V., Brasili C., Calia P., Reverberi P. M. (2017), Report on regional case-studies, PERCEIVE Deliverable 1.1, PERCEIVE project (GA nr. 693529), www.perceiproject.eu

Barberio, V., Mollona, E., Pareschi, L. (2017), Short contribution (report) to be used in dissemination events about the empirical relevance of a social constructivist and discursive approach to EU identity emergence and integration. PERCEIVE Deliverable 5.1, PERCEIVE project (GA nr. 693529). DOI:10.6092/unibo/amsacta/5619

Bauhr M. and Charron N. (2019), The EU as a savior and a saint? Corruption and public support for redistribution, Journal of European Public Policy, DOI: 10.1080/13501763.2019.1578816

Bauhr, M. and Charron N. (2018), What do citizens think about redistribution and aid within the EU? Description and highlights of a Pan-European citizen survey on public support for Cohesion Policy, QoG Working Paper Series 2018.2 (2018): 2

Bergbauer, S. (2018), Explaining European Identity Formation, Springer: Netherlands.

Borz, G., Brandenburg, H. and Mendez, C., 2018. The Impact of EU Cohesion Policy on European identity: Results from the COHESIFY citizen survey.

Brasili, C., Calia, P. and Monasterolo, I., Profiling identification with Europe and the EU project in the European regions, Investigaciones Regionales, forthcoming.

Braun D. and Tausendpfund M. (2014) The impact of the Euro crisis on citizens' support for the European Union. Journal of European Integration 36(3): 231-245

Bruter, M. (2008), Legitimacy, Euroscepticism \& Identity in the European Union - Problems of Measurement, Modelling \& Paradoxical Patterns of Influence', Journal of Contemporary European Research, Vol. 4, No. 4, pp. 273-285.

Bruter, M. (2003), Winning Hearts and Minds for Europe: The Impact of News and Symbols on Civic and Cultural European Identity. Comparative Political Studies, 36(10), pp. 1148-79.

Capello, R. and Perucca G. (2019), Understanding citizen perception of European Union Cohesion Policy: the role of the local context, Regional Studies, 52:11, 1451-1463, DOI: 10.1080/00343404.2017.1397273

Charron, N. (2017), Report including the database development and implementation and how it supports all the project WPs, Deliverable 2.1, PERCEIVE Project (GA nr. 693529). DOI: $10.6092 /$ unibo/amsacta/5722 
Dąbrowski, M., Stead, D. and Mashhoodi, B., 2017. Towards a regional typology of EU identification. COHESIFY Research Paper, 6.

Habermas, J. (2011), Zur Verfassung Europas. Ein Essay. Berlin: Suhrkamp.

Hagenaars, J. A. and McCutcheon, A. L. (2002), Applied Latent Class Analysis, Cambridge University Press, Cambridge.

Hobolt, S. B., and De Vries, C. E. (2016), Public support for European integration, Annual Review of Political Science, 19, 413-432.

Lopez-Bazo, E. and Royuela, V. (2017), Mapping the determinants of EU citizen's perception and identification. PERCEIVE Deliverable 2.2, PERCEIVE project Project (GA nr. 693529). DOI:10.6092/unibo/amsacta/5765.

Mendez, C. and Batchler, J. (2017), European Identity and Citizen Attitudes to Cohesion Policy: What do we know? COHESIFY RESEARCH PAPER 1.

Royuela, V. (2018), Report on the construction of the CIEI indicator. Qualitative report with main findings from the survey and discussion of comparative results from the application of the indicator of perception in the different case study regions, PERCEIVE Deliverable 2.3, PERCEIVE Project (GA nr. 693529). DOI: 10.6092/unibo/amsacta/5801

Serricchio F., Tsakatika M. and Quaglia L. (2013) Euroscepticism and the Global Financial Crisis. Journal of Common Market Studies 51(1), 51-64.

Skrondal, A. and Rabe-Hesketh, S. (2004), Generalized latent variable modeling: multilevel, longitudinal and structural equation models, Chapman and Hall/CRC, Boca Raton.

Verhaegen, S., Hooghe, M. and Quintelier, E. (2014), European Identity and Support for European Integration: A Matter of Perceived Economic Benefits?, Kyklos, 64(2), 295-314.

Vermunt, J. K. (2003), Multilevel Latent Class Models, Sociological Methodology, 33, 213-239. 